\title{
Risk of acute exacerbation between acetaminophen and ibuprofen in children with asthma
}

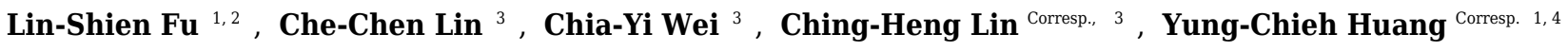 \\ 1 Department of Pediatrics, Taichung Veterans General Hospital, Taichung, Taiwan \\ 2 Department of Pediatrics, National Yang-Ming University, Taipei, Taiwan \\ 3 Department of Medical Research, Taichung Veterans General Hospital, Taichung, Taiwan \\ 4 Division of Pediatrics, Puli Branch, Taichung Veterans General Hospital, Nantou, Taiwan \\ Corresponding Authors: Ching-Heng Lin, Yung-Chieh Huang \\ Email address: epid@vghtc.gov.tw, huang1985john@yahoo.com.tw
}

Background. Antipyretics are widely prescribed in pediatric practice. Some reports have mentioned that acetaminophen and non-steroid anti-inflammatory drugs may negatively affect asthma control by causing asthma exacerbation (AE). However, many confounding factors can also influence the risks. We assessed the impact of using acetaminophen or ibuprofen on AE in asthmatic children, especially those with strong risk factors. Methods. We used the 2010 Taiwan National Health Insurance Research Database and identified 983 children with persistent asthma aged 1-5 years old; among them, 591 used acetaminophen alone and 392 used ibuprofen alone in 2010. Then, we analyzed the risk of $A E$ over 52 weeks in the patients with and without severe $A E$ in the previous year. Results. The ibuprofen group had a higher risk of an $E R$ visit or hospitalization for $A E$ (odds ratio $[\mathrm{OR}]=2.10,95 \%$ confidence interval $[\mathrm{Cl}]=1.17-3.76, P=0.01$ ). Among asthmatic children who had severe $A E$ in the previous year, the risk of $A E$ was higher in the ibuprofen group than in the acetaminophen group $(\mathrm{OR}=3.28,95 \% \mathrm{Cl}=1.30-8.29, P=$ 0.01 ), where as among those who did not, the risks of $A E$ were similar between the acetaminophen and ibuprofen groups $(\mathrm{OR}=1.52,95 \% \mathrm{Cl}=0.71-3.25, P=0.28)$.

Conclusions. Among young asthmatic children, use of ibuprofen was associated with a higher risk of $A E$ than acetaminophen, if they had severe $A E$ with $E R$ visit or hospitalization in the previous year. Pediatricians should use antipyretics among children with asthma after a full evaluation of the risk. 
1 Risk of acute exacerbation between acetaminophen and ibuprofen in children with asthma

2 Lin-Shien $\mathrm{Fu}^{1,2}$, Che-Chen Lin $^{3}$, Chia-Yi Wei ${ }^{3}$, Ching-Heng Lin ${ }^{3}$, Yung-Chieh Huang ${ }^{1,4}$

3 Affiliations: ${ }^{1}$ Department of Pediatrics, Taichung Veterans General Hospital, Taichung, Taiwan;

$4 \quad{ }^{2}$ Department of Pediatrics, National Yang-Ming University, Taipei, Taiwan; ${ }^{3}$ Department of

5 Medical Research, Taichung Veterans General Hospital, Taichung, Taiwan; ${ }^{4}$ Division of

6 Pediatrics, Puli Branch, Taichung Veterans General Hospital, Nantou, Taiwan.

\section{Corresponding authors:}

8

9 Yung-Chieh Huang, e-mail: huang1985john@yahoo.com.tw

10 Ching-Heng Lin, e-mail: epid@vghtc.gov.tw

11

12 Short Title: Risk of exacerbation in child with asthma

13

14 


\section{Abstract}

16 Background. Antipyretics are widely prescribed in pediatric practice. Some reports have

17 mentioned that acetaminophen and non-steroid anti-inflammatory drugs may negatively affect

18 asthma control by causing asthma exacerbation (AE). However, many confounding factors can

19 also influence the risks. We assessed the impact of using acetaminophen or ibuprofen on AE in

20 asthmatic children, especially those with strong risk factors.

21 Methods. We used the 2010 Taiwan National Health Insurance Research Database and

22 identified 983 children with persistent asthma aged 1-5 years old; among them, 591 used

23 acetaminophen alone and 392 used ibuprofen alone in 2010. Then, we analyzed the risk of AE

24 over 52 weeks in the patients with and without severe AE in the previous year.

25 Results. The ibuprofen group had a higher risk of an ER visit or hospitalization for AE (odds

26 ratio $[\mathrm{OR}]=2.10,95 \%$ confidence interval $[\mathrm{CI}]=1.17-3.76, P=0.01)$. Among asthmatic children

27 who had severe $\mathrm{AE}$ in the previous year, the risk of $\mathrm{AE}$ was higher in the ibuprofen group than in

28 the acetaminophen group $(\mathrm{OR}=3.28,95 \% \mathrm{CI}=1.30-8.29, P=0.01)$, where as among those who

29 did not, the risks of $\mathrm{AE}$ were similar between the acetaminophen and ibuprofen groups $(\mathrm{OR}=$

$30 \quad 1.52,95 \% \mathrm{CI}=0.71-3.25, P=0.28)$.

31 Conclusions. Among young asthmatic children, use of ibuprofen was associated with a higher

32 risk of $\mathrm{AE}$ than acetaminophen, if they had severe $\mathrm{AE}$ with $\mathrm{ER}$ visit or hospitalization in the 
33 previous year. Pediatricians should use antipyretics among children with asthma after a full

34 evaluation of the risk.

35

36

\section{Abbreviations:}

38 AE: asthma exacerbation

39 ER: emergency room

40 NHIRD: National Health Insurance Research Database

41 OR: odds ratio

42 OPD: outpatient department

43 CI: confidence interval

44 RTI: respiratory tract infection

45 ICS: inhaled corticosteroid

46 LTRA: leukotriene receptor antagonist

47 


\section{Introduction}

49 Acetaminophen and ibuprofen are the most widely used medications in children, the major

50 indication of their use being fever. Studies have suggested that the risk of asthma and wheezing

51 increases after acetaminophen use in several situations, including prenatal administration,

52 administration in infants, and exposure in the previous year.(L. B. Bacharier et al. 2008; F. J.

53 Gonzalez-Barcala et al. 2013; A. J. Henderson \& S. O. Shaheen 2013; E. Kreiner-Moller et al.

54 2012; M. Muc et al. 2013; A. R. Scialli et al. 2010; S. O. Shaheen et al. 2000; K. Thiele et al.

55 2013; G. W. Wong et al. 2007) However, none of these studies have reported on ibuprofen use,

56 even though it is another frequently used antipyretic. Furthermore, these studies did not rule out

57 the confounding effect of concurrent respiratory tract infection (RTI), which may play a more

58 important role in asthma than acetaminophen use.(E. Schnabel \& J. Heinrich 2010; J. E. Sordillo

59 et al. 2015) Studies assessing the influence of acetaminophen on lung function have shown

60 conflicting results in adults and children.(S. J. Ioannides et al. 2014; T. M. McKeever et al. 2005;

61 R. Soferman et al. 2013)

62 Studies comparing acetaminophen and ibuprofen for asthma control have also revealed

63 inconsistent results. Short-term use of acetaminophen for febrile illness in children aged 6

64 months to 12 years with asthma did not lead to more hospitalizations but did result in more

65 unscheduled outpatient department (OPD) visits for asthma exacerbation than ibuprofen use.(S. 
66 M. Lesko et al. 2002) However, after comparing the as-needed use of acetaminophen and

67 ibuprofen for 48 weeks, a recent double-blind randomized controlled study revealed no

68 difference in asthma control or asthma treatment with systemic corticosteroids in children aged

69 1-5 years with mild persistent asthma.(W. J. Sheehan et al. 2016) Matok and colleagues

70 examined the association between antipyretics and wheezing in children with febrile illness, and

71 found that ibuprofen was associated with a lower risk of wheezing.(I. Matok et al. 2017)

72 According to reports from the Global Initiative for Asthma, severe asthma exacerbation (AE) in

73 the past year is the strongest independent predictor of AE.(Global Initiative for Asthma 2017)

74 AE is defined as an acute or sub-acute episode of a progressive increase in asthma symptoms,

75 associated with airflow obstruction; the most commonly examined exacerbation outcomes are

76 the need for systemic corticosteroids and urgent unscheduled asthma-related care, specifically

77 ER visits, hospitalization, or unscheduled OPD visits.(N. G. Papadopoulos et al. 2012) In this

78 study, we used the Taiwan National Health Insurance Research Database (NHIRD) to compare

79 the risk of AE between1-year use of acetaminophen and 1-year use of ibuprofen in children aged

$801-5$ years with persistent asthma, focusing on the risk factors, including severe AE in the past

81 year.

82 Patients and Methods

83 Data source 
84 Taiwan established the National Health Insurance program in 1995, and more than 98\% of

85 Taiwan residents were insured under this system. The NHIRD was provided by the National

86 Health Research Institutes of Taiwan. The diagnostic codes in the database were based on the

87 International Classification of Diseases, Ninth Revision, Clinical Modification (ICD-9-CM). In

88 this study, we used the 2010 NHIRD, which contained the original claims data of 1000000

89 beneficiaries randomly sampled from the whole population.

\section{Study design}

91 Figure 1 presents a flowchart of patient inclusion in the study. There were 4444 pediatric asthma

92 cases in the database on January 1, 2010. The diagnosis of asthma was based on ICD-9-CM

93 493.X in at least 1emergency room (ER) visit, 1hospital admission, or 3 OPD visits, and the

94 asthma drugs used included inhaled corticosteroids (ICSs), leukotriene receptor antagonists

95 (LTRAs), systemic corticosteroids, and short-acting $\beta$-agonists (SABAs).

96 The primary endpoint of this study was development of AE, which was identified on the basis of

97 an ER visit or hospital admission with a primary ICD-9-CM code of 493.X within 1 year. We

98 considered $\mathrm{AE}$ and systemic corticosteroid treatment for asthma in the previous year as risk

99 factors in this study.

100 This study was approved by the institutional review board of Taichung Veterans General

101 Hospital (No. CE16220B). For the protection of privacy, the identities of the patients, physicians, 
102 and institutions were scrambled in accordance with the Personal Electronic Data Protection Law.

103

104 Statistical analysis

105 We evaluated the baseline characteristics of the patients with asthma, including age, sex, age at

106 asthma onset, asthma status, and medication status in the year preceding the baseline. Continuous

107 variables were expressed as the mean \pm standard deviation, and the difference between 2 groups

108 was assessed using the $t$ test. Categorical variables were calculated, and differences in the

109 distribution were assessed using the chi-square test. To compare the risks of AE between

110 acetaminophen and ibuprofen users, the odds ratios (ORs) and corresponding 95\% confidence

111 intervals (CIs) were estimated by using univariate and multivariate logistic regression models.

112 We also measured the cumulative incidence of AE in acetaminophen and ibuprofen users by

113 using the Kaplan-Meier method and tested differences in the curves by using the log-rank test.

114 The incidence curves were drawn using R software (R Foundation for Statistical Computing,

115 Vienna, Austria), and data management and statistical analyses were performed using SAS 9.4

116 (SAS Institute, Cary, NC, USA). A 2-sided $P$ value of $<.05$ was set as the significance level.

117

118 Results

119 Table 1 summarizes the demographic characteristics of the 2 groups. After excluding patients 
120 who had no asthma-related prescription $(n=69)$, those with severe systemic diseases $(n=74)$,

121 mixed antipyretic users $(\mathrm{n}=3181)$, and those with no acetaminophen or ibuprofen prescription

$122(\mathrm{n}=137), 591$ children with acetaminophen prescription alone and 392 with ibuprofen

123 prescription alone remained. The mean age of the patients in the ibuprofen group was lower than

124 that in the acetaminophen group ( $4.0 \pm 0.9 \mathrm{vs} 4.2 \pm 0.9 \mathrm{y}, P=0.008)$, and the ibuprofen group had a

125 higher percentage of boys $(67.1 \%$ vs $59.7 \%, P=0.02)$. There were no between-group differences

126 in age of asthma onset, severe AE (ER visit or hospitalization), frequency of upper RTI, or

127 asthma-related prescriptions including ICSs, LTRAs, and systemic corticosteroids.

128 We first analyzed some possible risk factors for AE after adjusting for age, sex, and patient

129 asthma and medication status in the previous year (Table 2). An ER visit or hospitalization in the

130 previous year was associated with a high risk $(\mathrm{OR}=10.6,95 \% \mathrm{CI}=5.90-18.9, P<0.0001)$. In

131 addition, the ibuprofen group had a higher risk of AE than did the acetaminophen group after

132 adjustment for sex, age, and patient status in the previous year $(\mathrm{OR}=2.10,95 \% \mathrm{CI}=1.17-3.16$,

$133 P=0.01)$. The ibuprofen group exhibited a significantly higher cumulative risk of AE from early

134 weeks to the end of the study period (Figure 2, $P=0.04$ ).

135 We then compared the risk of AE between patients in the acetaminophen and ibuprofen groups

136 who had systemic corticosteroid prescription and an asthma-related ER visit or hospitalization in

137 the previous year (Table 3). Among children who had an asthma-related ER visit or 
138 hospitalization in the previous year, those in the ibuprofen group had a higher risk of AE than did

139 those in the acetaminophen group $(\mathrm{OR}=3.28,95 \% \mathrm{CI}=1.30-8.29, P=0.01)$. In children with

140 no asthma-related ER visitor or hospitalization in the previous year, the risks of AE in both the

141 acetaminophen and ibuprofen groups were similar $(P=0.28)$. For children who had systemic

142 corticosteroid prescription in the previous year, the ibuprofen group had a higher risk of AE than

143 the acetaminophen group $(\mathrm{OR}=2.30,95 \% \mathrm{CI}=1.61-4.54, P=0.02)$. When we further analyzed

144 our results according to the patients' sex, we found that among female children (Table 3-1) with

145 asthma who had an asthma-related ER visit or hospitalization in the previous year, those in the

146 ibuprofen group had a higher risk of AE than did those in the acetaminophen group $(\mathrm{OR}=5.15$,

$14795 \% \mathrm{CI}=1.03-25.7, P=0.05)$. Among female children who had systemic corticosteroid

148 prescription in the previous year, the ibuprofen group had a higher risk of AE than the

149 acetaminophen group $(\mathrm{OR}=3.6,95 \% \mathrm{CI}=1.14-11.43, P=0.03)$. However, there were no

150 significant findings among male children with asthma (Table 3-2).

151 When we subdivided systemic corticosteroid prescription into OPD visits and ER visits or

152 hospitalization for asthma (Table 4), children receiving systemic corticosteroids in the OPD

153 showed similar risks of $\mathrm{AE}$ in the acetaminophen and ibuprofen groups $(P=0.55)$, whereas

154 among those receiving systemic corticosteroids in an ER visit or hospitalization, the risk was

155 higher in the ibuprofen group than in the acetaminophen group $(\mathrm{OR}=3.15,95 \% \mathrm{CI}=1.32-3.52$, 
$156 P=0.01)$.

157

158 Discussion

159 In this study, we identified children aged 1-5 years with asthma who received acetaminophen or

160 ibuprofen prescription alone for 52 weeks from the NHIRD to compare the rate of AE and

161 analyze the potential risks. We identified AE on the basis of an ER visit or hospitalization due to

162 asthma. The ibuprofen group exhibited a higher risk of an ER visit or hospitalization for asthma

163 and had significantly higher cumulative AEs over 52 weeks in our study. Among children who

164 had an ER visit or hospitalization in the previous year, the ibuprofen group carried a higher risk

165 of severe AE than the acetaminophen group. This difference was not evident in children who had

166 no ER visit or hospitalization for asthma in the previous year, regardless of whether they used

167 systemic corticosteroids.

168 We focused on antipyretics because they are the most frequently prescribed pediatric drugs.(L.

169 Vernacchio et al. 2009) From the data in the NHIRD, acetaminophen and ibuprofen account for

$17098.62 \%$ of antipyretic prescriptions in children 1-5 years old (unpublished data), and respiratory

171 infection is the most common condition associated with antipyretic use.(J. E. Sordillo et al. 2015)

172 The impacts of antipyretic prescription and respiratory infection on asthma control are a concern.

173 However, it is difficult and almost impossible not to use antipyretics when a child has a fever, 
174 and there are ethical concerns related to designing a clinical study to compare asthma control

175 between children using and not using antipyretics under such a condition. Studies comparing the

176 effects of different antipyretics on asthma control may provide valuable information for medical

177 decisions in clinical practice.

178 A few randomized, double-blind trials have compared acetaminophen and ibuprofen use for

179 asthma control.(S. M. Lesko et al. 2002; I. Matok et al. 2017; W. J. Sheehan et al. 2016) The

180 Boston University Fever Study evaluated the rates of hospitalization and outpatient visits for

181 asthma among children who had asthma and a febrile illness within 4 weeks after receiving

182 acetaminophen or ibuprofen. Compared with the acetaminophen group, the ibuprofen group had

183 fewer outpatient visits but no difference in asthma-related hospitalization.(S. M. Lesko et al.

184 2002) The Acetaminophen versus Ibuprofen in Children with Asthma (AVICA) trial was a long-

185 term study that followed children aged 1-5 years for 52 weeks; it found no difference in AE, as

186 evaluated by the intake of systemic corticosteroids, in groups receiving acetaminophen or

187 ibuprofen alone.(W. J. Sheehan et al. 2016) Riley and colleagues are recruiting for a randomized

188 controlled trial of acetaminophen versus ibuprofen use during infancy and its association with

189 the risk of asthma.(J. Riley et al. 2016) In the present NHIRD study, which also examined

190 children with asthma taking ibuprofen or acetaminophen over 52 weeks in 2010, no difference in

191 AE between the 2 groups was found with respect to systemic corticosteroid use. However, we 
192 found that the ibuprofen group had a higher rate of asthma ER visits or hospitalization, which

193 frequently occurred within 4 weeks of taking the antipyretic during our study period.

194 Sordillo et al demonstrated that RTIs might confound the relationship between infant antipyretic

195 use and early childhood asthma.(J. E. Sordillo et al. 2015) Other studies adjusting for RTIs when

196 analyzing early-life acetaminophen use and asthma have showed similar results.(A. J. Lowe et al.

197 2010; E. Schnabel \& J. Heinrich 2010) The AVICA trial found that RTIs carry higher risks of

198 antipyretic use and AE.(W. J. Sheehan et al. 2016) The Boston University Fever Study(S. M.

199 Lesko et al. 2002) also considered RTIs. In our study, the frequencies of RTI in the study period

200 and the previous year were similar between the acetaminophen and ibuprofen groups.

201 Factors contributing to AE include poor asthma control, severe exacerbation in the past year,

202 viral infection, allergen exposure, virus-allergen interaction, smoking, and air pollution. Among

203 these factors, severe exacerbation in the past year is the strongest independent factor.(L. S. Fu \&

204 M. C. Tsai 2014; A. Fuhlbrigge et al. 2012) Our study focused on severe AE as indicated by

205 asthma-related ER visits or hospitalization in the previous year, which was not analyzed in

206 previous studies. There is no "urgent OPD care" in the current health care system in Taiwan;

207 therefore, we included only ER visits and hospitalization. Concerning the need for systemic

208 corticosteroids, the AVICA trial had 4 scenarios for initiating systemic corticosteroids - poor

209 asthma control, an unscheduled visit to the OPD or ER due to asthma, hospitalization, and 
210 physicians' discretion. The present study could identify systemic corticosteroid use only in OPD

211 visits, ER visits, and hospitalization.

212 Several studies have investigated the effects of acetaminophen on lung function. Ioannides et al

213 showed no significant effect of 12-week-long acetaminophen intake (1g bid) on bronchial

214 hyperresponsiveness in adults with asthma.(S. J. Ioannides et al. 2014) Soferman et al

215 administered children with asthma $15 \mathrm{mg} / \mathrm{kg}$ acetaminophen and then performed spirometry and

216 measured fractional exhaled nitric oxide 60 minutes later. The results were not different from

217 those of the control group.(R. Soferman et al. 2013) Matok and colleagues conducted a cross-

218 sectional study on the association between antipyretics and wheezing in children with febrile

219 illness(I. Matok et al. 2017); in multivariate analysis, they found that ibuprofen was associated

220 with a lower risk of wheezing.

221 Several biological mechanisms underlying acetaminophen-induced asthma development and

222 acute attack have been proposed.(A. J. Henderson \& S. O. Shaheen 2013) In vitro and animal

223 studies have revealed that $N$-acetyl- $p$-benzoquinone imine (NAPQI), one of the metabolites of

224 acetaminophen, leads to the depletion of glutathione, which acts as an important antioxidant in

225 the airways; further epithelial damage and airway inflammation may occur. Acetaminophen may

226 also lead to preferential Th2 cytokine responses as it decreases intracellular glutathione levels

227 and modulates cytokine production in human alveolar macrophages and type II pneumocytes in 
228 vitro.(S. Dimova et al. 2005) Furthermore, aspirin and most non-steroid anti-inflammatory drugs,

229 including ibuprofen, inhibit cyclo-oxygenase-1 (COX-1) activity. This may lead to dysregulation

230 of arachidonic acid metabolism and eventually the clinical symptoms of non-steroid anti-

231 inflammatory drug-exacerbated respiratory diseases (NERDs),(R. A. Simon et al. 2015)

232 previously known as aspirin-exacerbated respiratory diseases. A meta-analysis for NERD

233 showed its prevalence to be $9 \%$ in adults.(D. R. Morales et al. 2015) Studies have found ROS-

234 related and TL4 gene polymorphisms to be significantly associated with the effects of

235 acetaminophen use in asthma.(S. H. Kang et al. 2013; S. H. Lee et al. 2014) In this study, we

236 found a stronger effect of ibuprofen in the children with asthma.

237 This study has some limitations. In clinical practices, there are no golden standards in diagnosing

238 asthma among patients under 5 years old except for recurrent symptoms and physicians'

239 judgement; however, the methodology used in this study was similar and even more rigorous

240 than previous published literatures (Y. C. Hung et al. 2014; J. Y. Wang et al. 2013; W. C. Wang

241 et al. 2017). There was a lack of data on the immunoglobulin E level, total eosinophil count, and

242 aeroallergen sensitization; however, no study has shown that the atopic condition influences the

243 effect of antipyretics on asthma control. This study is a retrospective database analysis, and we

244 could not be clear if the patients did take the antipyretics or evaluate the cumulative antipyretic

245 dose; however, the AVICA trial found that the cumulative antipyretic dose is not related to 
246 asthma control.(W. J. Sheehan et al. 2016) This study focused on children with persistent asthma

247 aged 1-5 years old, so the results may not be applied to other age groups or children with

248 intermittent to mild asthma.

249 Conclusions

250 In conclusion, this study using the NHIRD showed that an ER visit or hospitalization for asthma

251 is a major risk factor for AE. Ibuprofen carries a higher risk of AE than acetaminophen in

252 children with asthma, especially for those who have severe AE with an ER visit or

253 hospitalization, or systemic corticosteroid prescription in the previous year. We suggest that

254 studies analyzing the risk of antipyretics in asthma control consider severe AE in the previous

255 year. In clinical practice, it is difficult to avoid prescribing antipyretics to febrile children, but

256 pediatricians should use antipyretics after full evaluation of children with asthma and be cautious

257 of the risk of $\mathrm{AE}$.

258

259 Acknowledgment: This study is based in part on data from the National Health Insurance

260 Research Database provided by the National Health Insurance Administration, Ministry of

261 Health and Welfare and managed by National Health Research Institutes (Registered number

262 101095, 102148). The interpretation and conclusions contained herein do not represent those of

263 National Health Insurance Administration, Ministry of Health and Welfare or National Health 
264 Research Institutes.

265 The authors would like to thank the Healthcare Service Research Center of Taichung Veterans

266 General Hospital for statistical support.

267 This manuscript was edited by Wallace Academic Editing.

268

269 
270

271

272

273

274

275

276

277

278

279

280

281

282

283

284

285

286

287

288

289

290

291

292

293

294

295

296

297

298

299

300

301

302

303

304

\section{References:}

Asthma GIf. 2017. 2017 GINA Report, Global Strategy for Asthma Management and Prevention. Available at http://ginasthma.org (accessed July 25 2017).

Bacharier LB, Phillips BR, Zeiger RS, Szefler SJ, Martinez FD, Lemanske RF, Jr., Sorkness CA, Bloomberg GR, Morgan WJ, Paul IM, Guilbert T, Krawiec M, Covar R, Larsen G, Mellon M, Moss MH, Chinchilli VM, Taussig LM, and Strunk RC. 2008. Episodic use of an inhaled corticosteroid or leukotriene receptor antagonist in preschool children with moderateto-severe intermittent wheezing. J Allergy Clin Immunol 122:1127-1135.e1128. 10.1016/j.jaci.2008.09.029

Dimova S, Hoet PH, Dinsdale D, and Nemery B. 2005. Acetaminophen decreases intracellular glutathione levels and modulates cytokine production in human alveolar macrophages and type II pneumocytes in vitro. Int J Biochem Cell Biol 37:1727-1737. 10.1016/j.biocel.2005.03.005

Fu LS, and Tsai MC. 2014. Asthma exacerbation in children: a practical review. Pediatr Neonatol 55:83-91. 10.1016/j.pedneo.2013.07.004

Fuhlbrigge A, Peden D, Apter AJ, Boushey HA, Camargo CA, Jr., Gern J, Heymann PW, Martinez FD, Mauger D, Teague WG, and Blaisdell C. 2012. Asthma outcomes: exacerbations. J Allergy Clin Immunol 129:S34-48. 10.1016/j.jaci.2011.12.983

Gonzalez-Barcala FJ, Pertega S, Perez Castro T, Sampedro M, Sanchez Lastres J, San Jose Gonzalez MA, Bamonde L, Garnelo L, Valdes L, Carreira JM, Moure J, and Lopez Silvarrey A. 2013. Exposure to paracetamol and asthma symptoms. Eur J Public Health 23:706710. 10.1093/eurpub/cks061

Henderson AJ, and Shaheen SO. 2013. Acetaminophen and asthma. Paediatr Respir Rev 14:915; quiz 16. 10.1016/j.prrv.2012.04.004

Hung YC, Hung IL, Sun MF, Muo CH, Wu BY, Tseng YJ, and Hu WL. 2014. Integrated traditional Chinese medicine for childhood asthma in Taiwan: a Nationwide cohort study. BMC Complement Altern Med 14:389. 10.1186/1472-6882-14-389

loannides SJ, Williams M, Jefferies S, Perrin K, Weatherall M, Siebers R, Crane J, Patel M, Travers J, Shirtcliffe $P$, and Beasley R. 2014. Randomised placebo-controlled study of the effect of paracetamol on asthma severity in adults. BMJ Open 4:e004324. 10.1136/bmjopen2013-004324

Kang SH, Jung YH, Kim HY, Seo JH, Lee JY, Kwon JW, Kim BJ, Kim HB, Lee SY, Jang GC, Song DJ, Kim WK, Shim JY, Kim JH, Kang MJ, Yu HS, Yu J, and Hong SJ. 2013. Effect of paracetamol use on the modification of the development of asthma by reactive oxygen species genes. Ann Allergy Asthma Immunol 110:364-369.e361. 10.1016/j.anai.2013.03.008 
305

306

307

308

309

310

311

312

313

314

315

316

317

318

319

320

321

322

323

324

325

326

327

328

329

330

331

332

333

334

335

336

337

338

339

340

Kreiner-Moller E, Sevelsted A, Vissing NH, Schoos AM, and Bisgaard H. 2012. Infant acetaminophen use associates with early asthmatic symptoms independently of respiratory tract infections: the Copenhagen Prospective Study on Asthma in Childhood 2000 (COPSAC(2000)) cohort. J Allergy Clin Immunol 130:1434-1436. 10.1016/j.jaci.2012.09.017

Lee SH, Kang MJ, Yu HS, Hong K, Jung YH, Kim HY, Seo JH, Kwon JW, Kim BJ, Kim HJ, Kim YJ, Kim HS, Kim HB, Park KS, Lee SY, and Hong SJ. 2014. Association between recent acetaminophen use and asthma: modification by polymorphism at TLR4. J Korean Med Sci 29:662-668. 10.3346/jkms.2014.29.5.662

Lesko SM, Louik C, Vezina RM, and Mitchell AA. 2002. Asthma morbidity after the short-term use of ibuprofen in children. Pediatrics 109:E20.

Lowe AJ, Carlin JB, Bennett CM, Hosking CS, Allen KJ, Robertson CF, Axelrad C, Abramson MJ, Hill DJ, and Dharmage SC. 2010. Paracetamol use in early life and asthma: prospective birth cohort study. Bmj 341:c4616. 10.1136/bmj.c4616

Matok I, Elizur A, Perlman A, Ganor S, Levine H, and Kozer E. 2017. Association of Acetaminophen and Ibuprofen Use With Wheezing in Children With Acute Febrile Illness. Ann Pharmacother 51:239-244. 10.1177/1060028016678006

McKeever TM, Lewis SA, Smit HA, Burney P, Britton JR, and Cassano PA. 2005. The association of acetaminophen, aspirin, and ibuprofen with respiratory disease and lung function. Am J Respir Crit Care Med 171:966-971. 10.1164/rccm.200409-12690C

Morales DR, Guthrie B, Lipworth BJ, Jackson C, Donnan PT, and Santiago VH. 2015. NSAIDexacerbated respiratory disease: a meta-analysis evaluating prevalence, mean provocative dose of aspirin and increased asthma morbidity. Allergy 70:828-835. 10.1111/all.12629

Muc M, Padez C, and Pinto AM. 2013. Exposure to paracetamol and antibiotics in early life and elevated risk of asthma in childhood. Adv Exp Med Biol 788:393-400. 10.1007/978-94007-6627-3_53

Papadopoulos NG, Arakawa H, Carlsen KH, Custovic A, Gern J, Lemanske R, Le Souef P, Makela M, Roberts G, Wong G, Zar H, Akdis CA, Bacharier LB, Baraldi E, van Bever HP, de Blic J, Boner A, Burks W, Casale TB, Castro-Rodriguez JA, Chen YZ, El-Gamal YM, Everard ML, Frischer T, Geller M, Gereda J, Goh DY, Guilbert TW, Hedlin G, Heymann PW, Hong SJ, Hossny EM, Huang JL, Jackson DJ, de Jongste JC, Kalayci O, Ait-Khaled N, Kling S, Kuna P, Lau S, Ledford DK, Lee SI, Liu AH, Lockey RF, Lodrup-Carlsen K, Lotvall J, Morikawa A, Nieto A, Paramesh H, Pawankar R, Pohunek P, Pongracic J, Price D, Robertson C, Rosario N, Rossenwasser LJ, Sly PD, Stein R, Stick S, Szefler S, Taussig LM, Valovirta E, Vichyanond P, Wallace D, Weinberg E, Wennergren G, Wildhaber J, and Zeiger RS. 2012. 
341

342

343

344

345

346

347

348

349

350

351

352

353

354

355

356

357

358

359

360

361

362

363

364

365

366

367

368

369

370

371

372

373

374

375

376

International consensus on (ICON) pediatric asthma. Allergy 67:976-997.

10.1111/j.1398-9995.2012.02865.x

Riley J, Hunt A, McDouall A, Waqanivavalagi S, Braithwaite I, Weatherall M, Stanley T, Beasley R, Mitchell EA, and Dalziel SR. 2016. Pilot study of feasibility of a randomised controlled trial of asthma risk with paracetamol versus ibuprofen use in infancy. N Z Med J 129:3042.

Schnabel E, and Heinrich J. 2010. Respiratory tract infections and not paracetamol medication during infancy are associated with asthma development in childhood. J Allergy Clin Immunol 126:1071-1073. 10.1016/j.jaci.2010.08.023

Scialli AR, Ang R, Breitmeyer J, and Royal MA. 2010. Childhood asthma and use during pregnancy of acetaminophen. A critical review. Reprod Toxicol 30:508-519. 10.1016/j.reprotox.2010.09.005

Shaheen SO, Sterne JA, Songhurst CE, and Burney PG. 2000. Frequent paracetamol use and asthma in adults. Thorax 55:266-270.

Sheehan WJ, Mauger DT, Paul IM, Moy JN, Boehmer SJ, Szefler SJ, Fitzpatrick AM, Jackson DJ, Bacharier LB, Cabana MD, Covar R, Holguin F, Lemanske RF, Jr., Martinez FD, Pongracic JA, Beigelman A, Baxi SN, Benson M, Blake K, Chmiel JF, Daines CL, Daines MO, Gaffin JM, Gentile DA, Gower WA, Israel E, Kumar HV, Lang JE, Lazarus SC, Lima JJ, Ly N, Marbin J, Morgan WJ, Myers RE, Olin JT, Peters SP, Raissy HH, Robison RG, Ross K, Sorkness CA, Thyne SM, Wechsler ME, and Phipatanakul W. 2016. Acetaminophen versus Ibuprofen in Young Children with Mild Persistent Asthma. N Engl J Med 375:619-630. 10.1056/NEJMoa1515990

Simon RA, Dazy KM, and Waldram JD. 2015. Aspirin-exacerbated respiratory disease: characteristics and management strategies. Expert Rev Clin Immunol 11:805-817. 10.1586/1744666x.2015.1039940

Soferman R, Tsivion A, Farber M, and Sivan Y. 2013. The effect of a single dose of acetaminophen on airways response in children with asthma. Clin Pediatr (Phila) 52:4248. $10.1177 / 0009922812462764$

Sordillo JE, Scirica CV, Rifas-Shiman SL, Gillman MW, Bunyavanich S, Camargo CA, Jr., Weiss ST, Gold DR, and Litonjua AA. 2015. Prenatal and infant exposure to acetaminophen and ibuprofen and the risk for wheeze and asthma in children. J Allergy Clin Immunol 135:441-448. 10.1016/j.jaci.2014.07.065

Thiele K, Kessler T, Arck P, Erhardt A, and Tiegs G. 2013. Acetaminophen and pregnancy: shortand long-term consequences for mother and child. J Reprod Immunol 97:128-139. 10.1016/j.jri.2012.10.014

Vernacchio L, Kelly JP, Kaufman DW, and Mitchell AA. 2009. Medication use among children $<12$ 
377

378

379

380

381

382

383

384

385

386

387

388

years of age in the United States: results from the Slone Survey. Pediatrics 124:446-454. 10.1542/peds.2008-2869

Wang JY, Liu LF, Chen CY, Huang YW, Hsiung CA, and Tsai HJ. 2013. Acetaminophen and/or antibiotic use in early life and the development of childhood allergic diseases. Int $J$ Epidemiol 42:1087-1099. 10.1093/ije/dyt121

Wang WC, Lu ML, Chen VC, Ng MH, Huang KY, Hsieh MH, Hsieh MJ, McIntyre RS, Lee Y, and Lee CT. 2017. Asthma, corticosteroid use and schizophrenia: A nationwide population-based study in Taiwan. PLoS One 12:e0173063. 10.1371/journal.pone.0173063

Wong GW, Leung TF, Ma Y, Liu EK, Yung E, and Lai CK. 2007. Symptoms of asthma and atopic disorders in preschool children: prevalence and risk factors. Clin Exp Allergy 37:174-179. 10.1111/j.1365-2222.2007.02649.x 
Figure 1 (on next page)

Flowchart of patient inclusion in the study 


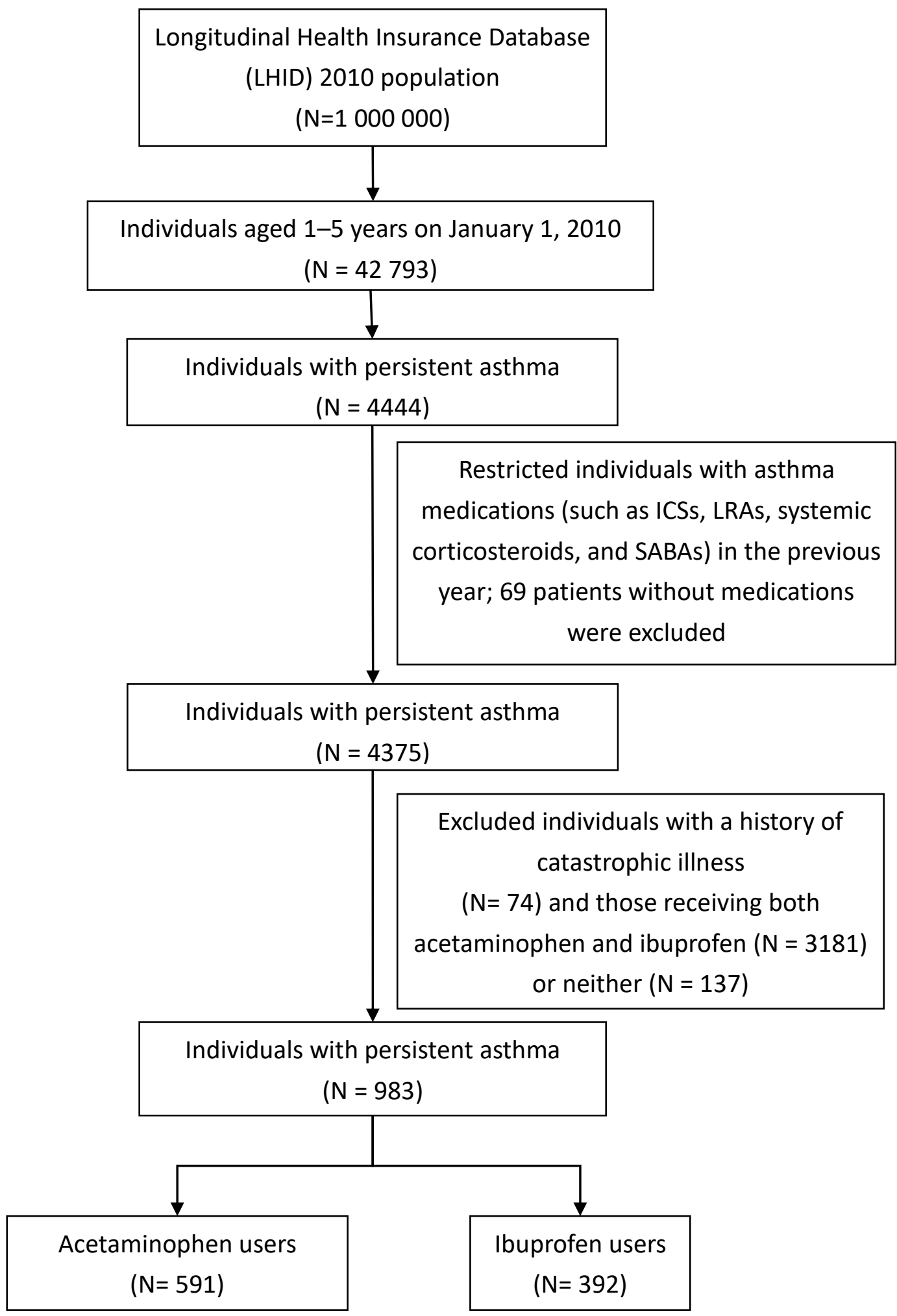


Figure 2

Cumulative risk of first $A E$ in acetaminophen and ibuprofen users

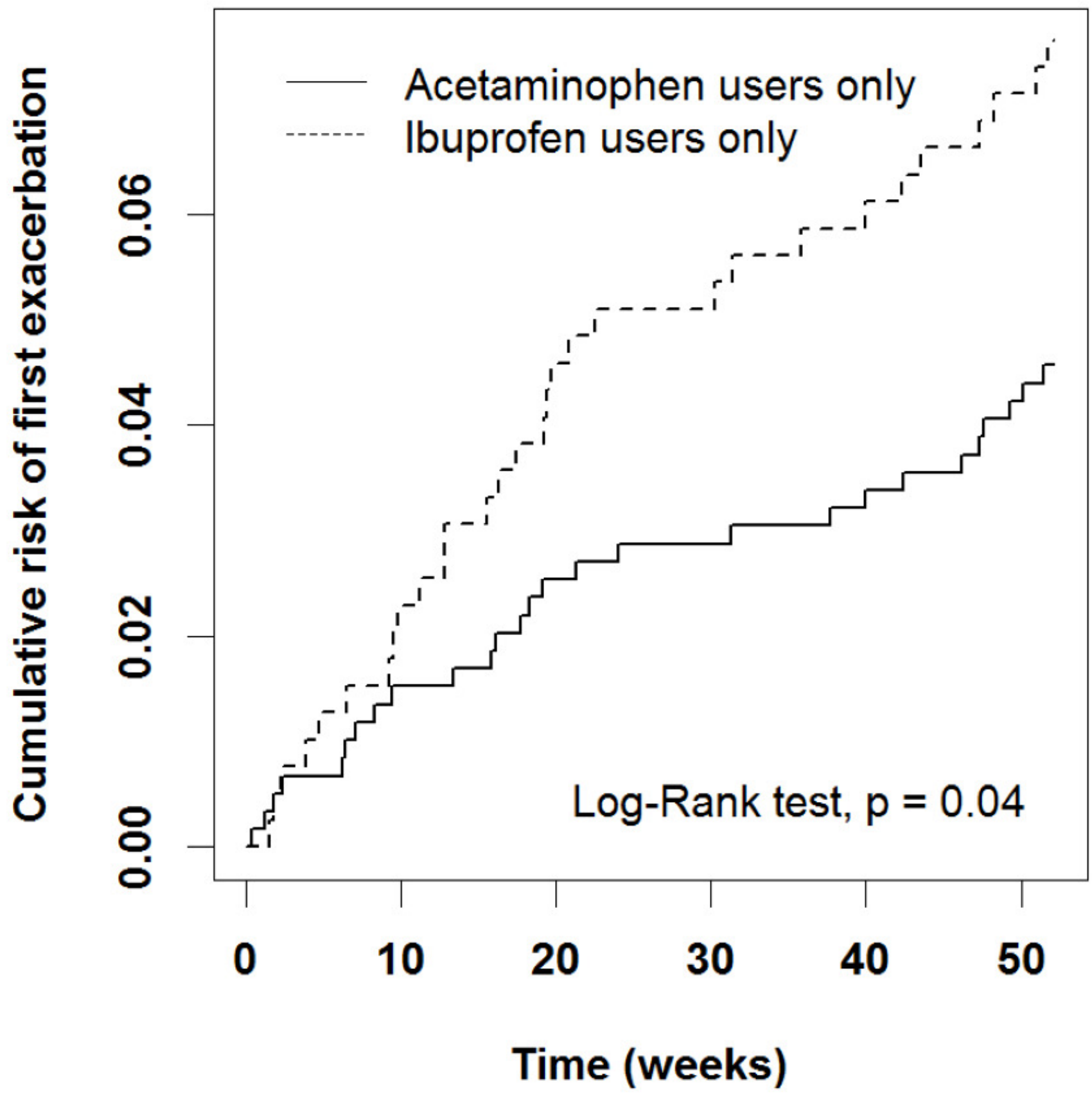




\section{Table 1 (on next page)}

Baseline Characteristics of Subgroups of Patients with Asthma 
1 Table 1: Baseline Characteristics of Subgroups of Patients with Asthma

\begin{tabular}{|l|c|c|c|}
\hline Variables & $\begin{array}{c}\text { Acetaminophen users } \\
\mathrm{N}=591\end{array}$ & $\begin{array}{c}\text { Ibuprofen users } \\
\mathrm{N}=392\end{array}$ & $p$-value \\
\hline Age, year (SD) & $4.2(0.9)$ & $4.0(0.9)$ & 0.008 \\
\hline Sex & $238(40.3)$ & $129(32.9)$ & 0.02 \\
\hline Female (\%) & $353(59.7)$ & $263(67.1)$ & \\
\hline Male (\%) & $26.5(13.2)$ & $25.3(13.3)$ & 0.15 \\
\hline $\begin{array}{l}\text { Age at onset of asthma, } \\
\text { month (SD) }\end{array}$ & $71(12.0)$ & $37(9.4)$ & 0.21 \\
\hline $\begin{array}{l}\text { Asthma exacerbation } \\
\text { status in the previous year } \\
\text { (\%) }\end{array}$ & $37(6.3)$ & $18(4.6)$ & 0.27 \\
\hline $\begin{array}{l}\text { Emergency visits for } \\
\text { asthma (\%) }\end{array}$ & $43(7.3)$ & $23(5.9)$ & 0.39 \\
\hline $\begin{array}{l}\text { Hospitalizations for } \\
\text { asthma (\%) }\end{array}$ & $150(25.4)$ & $115(29.3)$ & 0.17 \\
\hline $\begin{array}{l}\text { Medication status in the } \\
\text { previous year }\end{array}$ & $267(45.2)$ & $156(39.8)$ & 0.10 \\
\hline Use of ICS (\%) & $589(99.7)$ & $388(99.0)$ & 0.18 \\
\hline $\begin{array}{l}\text { Use of leukotriene } \\
\text { receptor antagonist (\%) }\end{array}$ & $116(19.6)$ & $61(15.6)$ & 0.10 \\
\hline $\begin{array}{l}\text { Use of systemic } \\
\text { corticosteroids (\%) }\end{array}$ & $158.5)$ & \\
\hline $\begin{array}{l}\text { Diagnosed upper } \\
\text { respiratory tract infection }\end{array}$ & & & 0.04 \\
\hline In the previous year (\%) & & & \\
\hline In 2010 (\%) & & & \\
\hline SD: stan & & & \\
\hline
\end{tabular}

2 SD: standard deviation

3 ICS: inhaled corticosteroids

4 


\section{Table 2 (on next page)}

Analysis of Risk Factors for AE 
1 Table 2: Analysis of Risk Factors for AE

\begin{tabular}{|c|c|c|c|c|}
\hline \multirow[t]{2}{*}{ Variables } & \multicolumn{2}{|c|}{ Asthma exacerbation } & \multirow{2}{*}{$\begin{array}{c}\text { Adjusted OR } \\
(95 \% \mathrm{CI})\end{array}$} & \multirow[b]{2}{*}{$p$-value } \\
\hline & No $(\%)$ & Yes $(\%)$ & & \\
\hline \multicolumn{5}{|l|}{ Antipyretics* } \\
\hline Acetaminophen & $564(60.9)$ & $27(47.4)$ & Reference & \\
\hline Ibuprofen & $362(39.1)$ & $30(52.6)$ & $2.10(1.17-3.76)$ & 0.01 \\
\hline Age, year [SD] & $4.1[0.9]$ & $3.8[0.9]$ & $0.80(0.60-1.07)$ & 0.13 \\
\hline \multicolumn{5}{|l|}{ Sex } \\
\hline Female & $346(37.4)$ & $21(36.8)$ & Reference & \\
\hline Male & $580(62.6)$ & $36(63.2)$ & $1.03(0.57-1.86)$ & 0.93 \\
\hline \multicolumn{5}{|c|}{$\begin{array}{l}\text { Patient status in the } \\
\text { previous year }\end{array}$} \\
\hline \multicolumn{5}{|l|}{ Asthma $\mathrm{AE}^{\ddagger}$} \\
\hline No & $846(91.4)$ & $29(50.9)$ & Reference & \\
\hline Yes & $80(8.6)$ & $28(49.1)$ & $10.6(5.90-18.9)$ & $<0.0001$ \\
\hline \multicolumn{5}{|l|}{$\begin{array}{l}\text { Use of systemic } \\
\text { corticosteroids }^{\#}\end{array}$} \\
\hline No & $547(59.1)$ & $13(22.8)$ & Reference & \\
\hline Yes & $379(40.9)$ & $44(77.2)$ & $3.07(1.56-6.05)$ & 0.001 \\
\hline
\end{tabular}

$2 *$ adjusted for age, sex, and patient status in the previous year (AE and use of systemic

3 corticosteroids)

$4 \neq$ adjusted for age, sex, and AE in the previous year

5 \# adjusted for age, sex, and use of systemic corticosteroids in the previous year

6 OR: odds ratios

7 CI: confidence intervals 


\section{Table 3(on next page)}

Risk of Acetaminophen and Ibuprofen Use in Subgroups of Children with Asthma 
1 Table 3: Risk of Acetaminophen and Ibuprofen Use in Subgroups of Children with Asthma

\begin{tabular}{|c|c|c|c|c|c|c|c|c|}
\hline & \multicolumn{4}{|c|}{ Without Asthma exacerbation in the previous year } & \multicolumn{4}{|c|}{ Asthma exacerbation in the previous year } \\
\hline & \multicolumn{2}{|c|}{ Asthma exacerbation } & \multirow{2}{*}{$\begin{array}{c}\text { Adjusted OR } \\
(95 \% \mathrm{CI})\end{array}$} & \multirow[b]{2}{*}{$p$-value } & \multicolumn{2}{|c|}{ Asthma exacerbation } & \multirow{2}{*}{$\begin{array}{c}\text { Adjusted OR } \\
(95 \% \mathrm{CI})\end{array}$} & \multirow[b]{2}{*}{$p$-value } \\
\hline Antipyretics & No $(\%)$ & Yes $(\%)$ & & & No $(\%)$ & Yes $(\%)$ & & \\
\hline Acetaminophen & $506(97.3)$ & $14(2.7)$ & \multicolumn{2}{|c|}{ Reference } & $58(81.7)$ & $13(18.3)$ & \multicolumn{2}{|c|}{ Reference } \\
\hline Ibuprofen & $340(95.8)$ & $15(4.2)$ & $1.52(0.71-3.25)$ & 0.28 & $22(59.5)$ & $15(40.5)$ & $3.28(1.30-8.29)$ & 0.01 \\
\hline & \multicolumn{4}{|c|}{ Non-use of systemic corticosteroids in the previous year } & \multicolumn{4}{|c|}{ Use of systemic corticosteroids in the previous year } \\
\hline & \multicolumn{2}{|c|}{ Asthma exacerbation } & Adjusted OR & & \multicolumn{2}{|c|}{ Asthma exacerbation } & Adjusted OR & \\
\hline & No $(\%)$ & Yes $(\%)$ & $(95 \% \mathrm{CI})$ & $p$-value & No $(\%)$ & Yes $(\%)$ & $(95 \% \mathrm{CI})$ & $p$-value \\
\hline Acetaminophen & $318(98.1)$ & $6(1.9)$ & \multicolumn{2}{|c|}{ Reference } & $246(92.1)$ & $21(7.9)$ & \multicolumn{2}{|c|}{ Reference } \\
\hline Ibuprofen & $229(97.0)$ & $7(3.0)$ & $1.71(0.56-5.29)$ & 0.35 & $133(85.3)$ & $23(14.7)$ & $2.30(1.16-4.54)$ & 0.02 \\
\hline
\end{tabular}

2 Model adjusted for age, sex, and patient status in the previous year (AE and use of systemic corticosteroids)

3 OR: odds ratios

4 CI: confidence intervals 
8 Table 3-1: Risk of Acetaminophen and Ibuprofen Use in Subgroups of Female Children with Asthma

\begin{tabular}{|c|c|c|c|c|c|c|c|c|}
\hline & \multicolumn{4}{|c|}{ Without Asthma exacerbation in the previous year } & \multicolumn{4}{|c|}{ Asthma exacerbation in the previous year } \\
\hline & \multicolumn{2}{|c|}{ Asthma exacerbation } & \multirow{2}{*}{$\begin{array}{c}\text { Adjusted OR } \\
(95 \% \mathrm{CI})\end{array}$} & \multirow[b]{2}{*}{$p$-value } & \multicolumn{2}{|c|}{ Asthma exacerbation } & \multirow{2}{*}{$\begin{array}{c}\text { Adjusted OR } \\
(95 \% \mathrm{CI})\end{array}$} & \multirow[b]{2}{*}{$p$-value } \\
\hline Antipyretics & No $(\%)$ & Yes $(\%)$ & & & No $(\%)$ & Yes $(\%)$ & & \\
\hline Acetaminophen & $204(65.0)$ & $7(63.6)$ & \multicolumn{2}{|c|}{ Reference } & $24(75.0)$ & $3(30.0)$ & \multicolumn{2}{|c|}{ Reference } \\
\hline \multirow[t]{4}{*}{ Ibuprofen } & $110(35.0)$ & $4(36.4)$ & $1.01(0.28-3.66)$ & 0.98 & $8(25.0)$ & $7(70.0)$ & $5.15(1.03-25.7)$ & 0.05 \\
\hline & \multicolumn{4}{|c|}{ Non-use of systemic corticosteroids in the previous year } & \multicolumn{4}{|c|}{ Use of systemic corticosteroids in the previous year } \\
\hline & \multicolumn{2}{|c|}{ Asthma exacerbation } & Adjusted OR & & \multicolumn{2}{|c|}{ Asthma exacerbation } & Adjusted OR & \\
\hline & No $(\%)$ & Yes $(\%)$ & $(95 \% \mathrm{CI})$ & $p$-value & No $(\%)$ & Yes $(\%)$ & $(95 \% \mathrm{CI})$ & $p$-value \\
\hline Acetaminophen & $130(62.8)$ & $4(80.0)$ & \multicolumn{2}{|c|}{ Reference } & $98(70.5)$ & $6(37.5)$ & \multicolumn{2}{|c|}{ Reference } \\
\hline Ibuprofen & $77(37.2)$ & $1(20.0)$ & $0.40(0.04-3.66)$ & 0.42 & $41(29.5)$ & $10(62.5)$ & $3.6(1.14-11.43)$ & 0.03 \\
\hline
\end{tabular}

9 Model adjusted for age, sex, and patient status in the previous year (AE and use of systemic corticosteroids)

10 OR: odds ratios

11 CI: confidence intervals 
Table 3-2: Risk of Acetaminophen and Ibuprofen Use in Subgroups of Male Children with Asthma

\begin{tabular}{|c|c|c|c|c|c|c|c|c|}
\hline \multirow[b]{3}{*}{ Antipyretics } & \multicolumn{4}{|c|}{ Without Asthma exacerbation in the previous year } & \multicolumn{4}{|c|}{ Asthma exacerbation in the previous year } \\
\hline & \multicolumn{2}{|c|}{ Asthma exacerbation } & \multirow{2}{*}{$\begin{array}{c}\text { Adjusted OR } \\
(95 \% \mathrm{CI})\end{array}$} & \multirow[b]{2}{*}{$p$-value } & \multicolumn{2}{|c|}{ Asthma exacerbation } & \multirow{2}{*}{$\begin{array}{c}\text { Adjusted OR } \\
(95 \% \mathrm{CI})\end{array}$} & \multirow[b]{2}{*}{$p$-value } \\
\hline & No $(\%)$ & Yes $(\%)$ & & & No $(\%)$ & Yes $(\%)$ & & \\
\hline Acetaminophen & $302(56.8)$ & $7(38.9)$ & \multicolumn{2}{|c|}{ Reference } & $34(70.8)$ & $10(55.6)$ & \multicolumn{2}{|c|}{ Reference } \\
\hline \multirow[t]{4}{*}{ Ibuprofen } & $230(43.2)$ & $11(61.1)$ & $1.93(0.72-5.14)$ & 0.19 & $14(29.2)$ & $8(44.4)$ & $2.49(0.76-8.18)$ & 0.13 \\
\hline & \multicolumn{4}{|c|}{ Non-use of systemic corticosteroids in the previous year } & \multicolumn{4}{|c|}{ Use of systemic corticosteroids in the previous year } \\
\hline & \multicolumn{2}{|c|}{ Asthma exacerbation } & Adjusted OR & & \multicolumn{2}{|c|}{ Asthma exacerbation } & Adjusted OR & \\
\hline & No $(\%)$ & Yes $(\%)$ & $(95 \% \mathrm{CI})$ & $p$-value & No $(\%)$ & Yes $(\%)$ & $(95 \% \mathrm{CI})$ & $p$-value \\
\hline Acetaminophen & $188(55.3)$ & $2(25.0)$ & \multicolumn{2}{|c|}{ Reference } & $148(61.7)$ & $15(53.6)$ & \multicolumn{2}{|c|}{ Reference } \\
\hline Ibuprofen & $152(44.7)$ & $6(75.0)$ & $3.67(0.72-18.8)$ & 0.12 & $92(38.3)$ & $13(46.4)$ & $1.86(0.78-4.43)$ & 0.16 \\
\hline
\end{tabular}

14 Model adjusted for age, sex, and patient status in the previous year (AE and use of systemic corticosteroids)

15 OR: odds ratios

16 CI: confidence intervals

17 


\section{Table 4(on next page)}

Analysis of Patients with Systemic Corticosteroid Prescription in the Previous Year 
1 Table 4: Analysis of Patients with Systemic Corticosteroid Prescription in the Previous Year

\begin{tabular}{|l|c|c|c|c|c|c|c|c|}
\hline & \multicolumn{4}{|c|}{ Only in OPD } & \multicolumn{3}{c|}{ In ER/hospitalization (with or without OPD) } \\
\hline & Asthma exacerbation & Adjusted OR & & Asthma exacerbation & Adjusted OR & Yes (\%) & $(95 \%$ CI) & $p$-value \\
\hline & No (\%) & Yes (\%) & $(95 \%$ CI) & $p$-value & No (\%) & Reference \\
\hline Acetaminophen & $190(96.9)$ & $6(3.1)$ & \multicolumn{2}{|c|}{ Reference } & $56(78.9)$ & $15(21.1)$ & \multicolumn{2}{|c|}{ Ref } \\
\hline Ibuprofen & $113(95.0)$ & $6(5.0)$ & $1.44(0.43-4.83)$ & 0.55 & $20(54.1)$ & $17(45.9)$ & $3.15(1.32-7.52)$ & 0.01 \\
\hline
\end{tabular}

2 Model adjusted for age, sex, and patient status in the previous year (AE and use of systemic corticosteroids)

3 OR: odds ratios

4 CI: confidence intervals

5 OPD: outpatient department

6 